\title{
History of Pandemic Vaccinations - From Concept to Commercial Use
}

\author{
Ansha Khurana ${ }^{1 *}$ and Aanya Bhatia ${ }^{2}$ \\ ${ }^{1}$ St Johns College, UK \\ ${ }^{2}$ Mission San Jose High School, USA \\ *Corresponding Author: Ansha Khurana, St Johns College, UK.
}

Received: October 21, 2020

Published: November 18, 2020

(C) All rights are reserved by Ansha Khurana

and Aanya Bhatia.

\begin{abstract}
History doesn't repeat itself but it often rhymes, as said Mark Twain. It often guides the future. The authors discuss some of the key historical pandemics and mankind's response to them, along with the development of pandemic vaccines. Currently the key strategy arguably rests on the discovery of a vaccine for Covid-19, presumably, the only escape route from the current crisis. While our scientists endeavour to find the vaccine, washing hands, social distancing and treatment advances remain the pillars for fighting COVID with a number of unsolved questions for any potential vaccines.
\end{abstract}

Keywords: Covid-19; Vaccines; Polio; Ebola

\section{Introduction}

The more you know about the past, the better you are prepared for the future, said Theodore Roosevelt. History might be a humanities subject, but there is nevertheless a scientific approach to its content, especially in the context of biomedical sciences [1]. As optimism gathers about the ongoing vaccine trials for COVID19 by Oxford and other world renowned institutions, researchers and the general population look towards the future. However, we peek into the past in an attempt to predict the future!

This article discusses some of the key historical pandemics and mankind's response to them, along with the development of pandemic vaccines that could potentially help us to understand the challenges we currently face. At this moment in time, the stakes could hardly be higher; and the key strategy arguably rests on the discovery of a vaccine for Covid-19 - presumably, the only escape route from the current crisis.

\section{History of vaccines}

The practice of immunisation dates back hundreds of years from Buddhist monks [2] in China to Ayurvedic [3] Indian texts. Traditional vaccines work by creating a weakened or killed form of the virus, similar enough to the original that the immune system will be forearmed if the person is exposed to a full infection in future. The approach has led to some of the most successful vaccines in our history, but carries an inherent risk as a newly developed attenuated virus may not be as innocuous as the hoped by the scientists [4]. Clinical trials have to be approached cautiously and slowly to ensure safety as well as efficacy, which is certainly not ideal in a pandemic given the race against time. This article discusses the alternatives later.

The term vaccine is derived from the Latin word for cow, reflecting the origins of the smallpox vaccination. Initially, the terms vaccine or vaccination referred only to smallpox, but in 1881 Louis Pasteur proposed that in honour of Edward Jenner, a late $18^{\text {th }}$ Century British doctor who discovered that milkmaids infected with cowpox seemed immune to smallpox, the terms were widened [5].

\section{Small pox}

Smallpox is thought to date back to the Egyptian Empire around the $15^{\text {th }}$ century BC based on a smallpox-like rash found on three mummies [6]. It was endemic to Europe, Asia and Arabia for centuries, killing $30 \%$ of those infected, and leaving the survivors with scars! Jenner famously inoculated his gardener's 9-year-old son, James Phipps with cowpox from a local milkmaid and then exposed 
him to the smallpox virus with no ill effect. However, Jenner was not the first to try cowpox inoculation but was the first to publish his evidence and distribute the vaccine freely [7].

The smallpox vaccine was the first vaccine to be developed against a contagious disease but it was only in 1980, after a global vaccination campaign, almost two centuries after the invention of the vaccine, that the WHO declared smallpox eradicated from the face of the earth. This is often considered as one the most remarkable feats in public health in the history of humankind [7], especially as the scientific community continues to strive hard to achieve similar results in several other common infections.

\section{Plague}

The 'Bubonic Plague' is an infectious disease caused by the bacillus Yersinia pestis, a very pathogenic organism which is still endemic in rodent populations of Americas, Africa and Central Asia [8]. In epidemics, plague is transmitted to humans by the fleas on the rats.

Yersinia Pestis caused three of the deadliest pandemics in the recorded history. The first plague pandemic was as far back as in $541 \mathrm{AD}$ and lasted 8 years. Originating in central Africa and spreading to the rest of the world, this plague was responsible for the loss of 15-100 million lives [8,9], roughly half of the world's population. To make matters worse, aside from the horrific death toll that shook the globe, the Justinian Plague was only the first of about eighteen waves in the first plague pandemic series [9]. If one was to compare with that to the current COVID-19 pandemic, it would probably give a very optimistic feel.

The second pandemic plague kicked off with the infamous Black death of 1346 [9]. It claimed 75-200 million lives, originating in Asia and spreading possibly through merchant ships [10]. This plague became endemic in most places but unfortunately, London never really got rid of it for a long time. The plague resurfaced roughly every 20 years from 1348 to 1665 - a total of forty outbreaks in three hundred years. In each new plague epidemic, 20\% of London's population was wiped out. Three hundred years later, the Great Plague of 1665 was the last and one of the worst ones, killing quarter of Londoners in just seven months [11]. It must be the population density and people's movement in London that resulted in the epidemic to be intense and wide spread even hundreds of years ago.
Many of the techniques used to battle COVID-19 result because of the lessons learnt from centenaries of this contagion. While there was no scientific understanding, people realised the importance of proximity or 'social distancing'. That's why forward-thinking officials in Venetian port city decided to keep newly arrived sailors in isolation until they could prove they weren't sick- the very first quarantine [10], something that the current governments are trying to formulate. England also imposed a 'lockdown', banning all public events and introduced laws to separate and isolate the sick. Homes stricken by plague were marked with a bale of hay strung to a pole outside. If one had infected family members, they had to carry a white pole when going out in public [12] - an analogue version of the track and trace app!

Despite the Series of Pandemic Plagues there is no vaccine to date, though there is treatment with antibiotics. Centuries of the fight with plague has been won not on the basis of a vaccine, but better sanitation and use of antibiotics. This helps us to realise that there may never be a successful vaccine to COVID-19 but rather a treatment like with plague, Malaria, and HIV, which still remain an enigma to scientists so far as vaccine development is concerned.

Polio

The first major polio epidemic in the United States occurred in 1894 and the world saw sporadic epidemics of polio in the early twentieth century until a vaccine was later developed in 1954, at least 60 years after the first major outbreak. Before that 1935 two separate teams, had developed polio vaccines and reported their results at an annual scientific meeting of in the US. The principle was to inject killed polio virus. Despite promising results, both trials were cancelled as a result of the angry reaction from other researchers, as vaccinated children had died in both studies [13]. Annual cases increased in the US and a big surge was seen in 1952 and 53 . The high number of cases reignited the race for a vaccine and millions of dollars were invested. However, the principle abandoned 20 years ago was used again by Jonas Salk who developed his successful vaccine in 1954 [14]. Another vaccine, based on live but attenuated virus was developed around the same time by Sabin [15]. Because Salk's vaccine had been started to be used successfully in the United States, Sabin was not able to get support for a large-scale, controlled field trial and had to move to Russia and Mexico for the same.

The two vaccines, by Salk and Sabin, have eliminated polio from most of the world, with the last polio case in the United States be-

Citation: Ansha Khurana and Aanya Bhatia. "History of Pandemic Vaccinations - From Concept to Commercial Use". Acta Scientific Medical Sciences 4.12 (2020): 34-37. 
ing reported in 1979 and only 22 reported cases in 2017 in the whole world [16]. A remarkable feat - and another battle won only after decades of hard work and dedication of scientists, clinicians and volunteers.

\section{Ebola}

Interestingly, an Ebola vaccine was in fact developed much before the pandemic in 2014 but never trialled on humans due to lack of funding and commercial viability. Ebola was sporadic only in pockets in Africa and did not pose a threat to the World until 2014 to consider major investment in its vaccine. The vaccine was used under emergency protocol after hastened trails after the pandemic in 2015 to curb it. It eventually gained approval in 2019, five years after the Pandemic. The collaboration and complex negotiations between the countries and different pharmaceutical companies was deemed an unparalleled achievement [17]. This is remarkable as the full approval was not feasible for over four years of its initial use during the pandemic. It is entirely likely that COVID-19 vaccine follows the same course by being used under the emergency protocol. Some relief however could be drawn from the fact that the Ebola vaccine was effective in controlling the epidemic and is not known to have caused any significant or unexpected complications even after full trails and human use with only emergency testing during the pandemic times.

\section{Influenza/Flu}

There are four varieties of influenza viruses. Influenza A and B are the most well-known strains and are the ones that cause the annual epidemics and typically only one of them comes a year, usually type A. Influenza C causes a mild respiratory illness and doesn't typically cause epidemics. Finally, influenza D mostly affects cattle and, at least for now, is not known to infect people [18].

Each Influenza A virus is defined based on two proteins: the envelope of the virus: hemagglutinin (the H in H1N1) and neuraminidase (the $\mathrm{N}$ in H1N1). Both must be present for the virus to reproduce. Hemagglutinin helps the virus attach to the cells in the body, and neuraminidase allows the virus to be released from the host cell once it has replicated - ultimately spreading the infection. The figures determine the subtype of hemagglutinin and neuraminidase proteins. Currently, there are 18 known hemagglutinin subtypes (H1 to H18) and 11 known neuraminidase subtypes (N1 to N11), according to the CDC [18].

The difficulty with creating influenza vaccines is that the RNA virus is constantly mutating through antigenic drift or antigenic shift. As the name implies, antigenic drift is a process in which small changes to the virus's genes are made over time as it repro- duces. Because these changes are small, the new viruses are closely related to the original virus. However, over time, these changes can proliferate and ultimately result in a completely foreign virus that the body might not recognize. Antigenic shift, on the other hand, is the method by which two or more distinct strains of Influenza, combine to form a new subtype, having a mixture of the surface antigens of the two or more original strains. This property is unique to Influenza A. This means that it can result in new hemagglutinin or neuraminidase proteins. When this happens, the entire section of the genome has altered, meaning that the very subtype of the virus has changed completely [18].

This understanding leads us on to the previous pandemic in 2009, the Swine Flu. In the spring of 2009 in Mexico, an antigenic shift occurred to the circulating flu strain, H1N1, and a completely new virus emerged to which people had little or no protection. That particular strain was so severe because it was a combination of swine, human, and bird flu viruses. Nearly 61 million people were infected and 284,000 were killed during the Pandemic.

Other Influenza pandemics include the 1918 Spanish flu which was the first of the H1N1 pandemics. This lasted from January 1918 to December 1920 and claimed 20 to 50 million lives. The Asian Flu or H2N2 strain emerged from Asia in February 1957 and claimed 1.1 million lives. The 1968 H3N2 was yet another pandemic and a fine example of the genetic offshoot of the H2N2 version also resulted in one million deaths despite having a mortality rate of $0.5 \%$ but this strain continues to circulate each year [18].

This technique of inoculating the virus in chicken eggs was first used by Jonas Salk, the developer of the poliovirus vaccine, in 1938 to protect the U.S. military forces against the flu during World War II. Vaccines produced from the 1940s to the 1960s were not as purified as more modern vaccines, and the impurities in vaccines were thought to contribute to side effects such as fever, aches, and fatigue [19]. Scientist are now exploring the possibility of inoculating flu in animals cells. This technique is expected to be more scalable and avoid problems with eggs, such as allergic reactions and incompatibility with strains that affect avian like chickens [20]. Much of the research these days relies on the fast-track idea that the immune system doesn't really need to see the entire virus - live or killed. Known as a subunit vaccine - wherein if the virus is the warship, the theory is that the immune system needs only to see the enemy flag to form an immune memory. In the case of Covid-19, this flag is the spike protein that forms a halo or "corona" around the virus [4].

In the $2009 \mathrm{H} 1 \mathrm{~N} 1$ pandemic, health researchers accelerated the normal developing, testing, and manufacturing processes so that 
sufficient quantities of the vaccine could be provided. The World Health Organisation had estimated the overall production capacity to be around three billion doses of the H1N1 vaccine over a twelve month period, which would have covered less than half the world population [21]. Similar would be the expected capacity for the current COVID-19 situation. In addition, the scientists remain vigilant for new strains of the seasonal flu as well as any shift in the COVID-19. Even if a vaccine was developed imminently, the pharmaceutical companies would need to make several billions cover a large proportion of the world population especially if two doses were required to achieve effective immunisation.

\section{Conclusion}

It is very likely that should a COVID vaccine be made, it would be used under a similar emergency protocol without full licence and approval as in previous pandemics. While our scientists endeavour to find the vaccine, washing hands, social distancing and treatment advances remain the pillars for fighting COVID. The big questions still remain - if and when the vaccine come to fruition? How long would it be effective - a season, a year or life long? And importantly, could the virus mutate and come back each year?

\section{Bibliography}

1. Sugand K., et al. "History lessons in medical education: A current necessity?" Surgical Practice 17.1 (2013): 18-21.

2. Boylston A. "The origins of inoculation". Journal of the Royal Society of Medicine 105.7 (2012): 309-313.

3. Adelon. Chaumeton FP, Mérat de Vaumartoise FV (eds.). "Inoculation”. Dictionnaire des Sciences Médicales. Paris: C.L.F. Panckoucke (1818).

4. https://www.theguardian.com/world/2020/apr/24/thehunt-for-a-coronavirus-vaccine-a-perilous-and-uncertainpath

5. Berche P. "Louis Pasteur, from crystals of life to vaccination". Clinical Microbiology and Infection 18.5 (2012): 1-6.

6. EUGEN S. "Traces of a Small Pox epidemic in the family of Ramesses V of the Egyptian 20th Dynasty". Anthropologie 34.3 (1996): 315-319.

7. Fenner F., et al. Smallpox and Its Eradication (History of International Public Health, No. 6) (PDF). Geneva: World Health Organization 264 (1988): 1261-1262.

8. Jefferson T., et al. "Vaccines for preventing plague". Cochrane Database System Review 1998.2 (2000): CD000976.

9. Mordechai L., et al. "The Justinianic Plague: An inconsequential pandemic?". Proceedings of the National Academy of Sciences of the United States of America 116.51 (2019): 25546-25554.
10. White CF. "Plague: Modern Preventive Measures in Ships and Ports: (Section of Tropical Diseases and Parasitology)". Journal of the Royal Society of Medicine 28.5 (1935): 591-602.

11. Stanbridge N. "DNA confirms cause of 1665 London's Great Plague".

12. https://www.history.com/news/pandemics-end-plaguecholera-black-death-smallpox

13. Offit PA. “The Cutter Incident: How America's First Polio Vaccine Led to the Growing Vaccine Crisis". Yale University Press (2017): 38.

14. Juskewitch JE., et al. "Lessons from the Salk polio vaccine: methods for and risks of rapid translation". Clinical and Translational Science (Review) 3.4(2010): 182-185.

15. Sabin AB., et al. "Landmark article Aug 6, 1960: Live, orally given poliovirus vaccine. Effects of rapid mass immunization on population under conditions of massive enteric infection with other viruses". JAMA 251.22 (1984): 2988-2993.

16. https://www.cdc.gov/polio

17. Wolf J., et al. "Applying lessons from the Ebola vaccine experience for SARS-CoV-2 and other epidemic pathogens". NPJ Vaccines 5.51 (2020).

18. https://www.cdc.gov/flu/about/viruses/index.htm

19. https://www.emedicinehealth.com/flu_vaccine

20. Chen J., et al. "Better influenza vaccines: an industry perspective". Journal of Biomedical Science 27.33 (2020).

21. "Transcript of virtual press conference with Gregory Hartl, Spokesperson for H1N1, and Dr Marie-Paule Kieny, WHO Director of the Initiative for Vaccine Research, World Health Organization" World Health Organization (2009).

\section{Assets from publication with us}

- Prompt Acknowledgement after receiving the article

- Thorough Double blinded peer review

- Rapid Publication

- Issue of Publication Certificate

- High visibility of your Published work

Website: www.actascientific.com/

Submit Article: www.actascientific.com/submission.php Email us: editor@actascientific.com

Contact us: +919182824667 